\title{
Research on Improving the Innovation Ability of College Students Based on Project Driven Method
}

\author{
Shujuan $\mathrm{Li}^{1, \mathrm{a}, *}$, Yanrong Tong ${ }^{1, \mathrm{~b}}$ and Yan $\mathrm{Su}^{1, \mathrm{c}}$ \\ ${ }^{I}$ School of Physics and Technology, University of Jinan, Jinan, Shandong Province, China \\ ${ }^{a}$ ss_lisj@ujn.edu.cn, ${ }^{b}$ ss_tongyr@ujn.edu.cn, ${ }^{c} s s_{\_}$suy@ujn.edu.cn \\ *Corresponding author
}

\begin{abstract}
The cultivation of innovation ability is an important part of the quality of talent cultivation in Colleges and Universities at present. In this study, a series of reforms and attempts have been carried out in the course of "Principle and application of sensors" by using the project driven method and the "rain classroom" intelligent teaching platform, and good results have been achieved. Based on the analysis of the current situation of curriculum, this paper expounds the ideas of curriculum reform. The study focuses on the teaching practice of curriculum reform, including the efforts and attempts in the construction of teaching resource base, the construction of project driven teaching method, and the construction of diversified assessment and evaluation system. The application of the blended teaching mode makes the project driven effect obvious, and the project design combined with the course content closely plays a positive role in improving the innovation ability of college students.
\end{abstract}

Keywords: project driven method, innovation ability, "rain classroom", blended teaching, sensor

\section{基于项目驱动法提升大学生创新能力研究}

\author{
李淑娟 ${ }^{1, a, *}$ ，童艳荣 ${ }^{1, b}$ ，苏燕 ${ }^{1, c}$
}

\author{
${ }^{1}$ 物理科学与技术学院, 济南大学, 济南, 山东, 中国 \\ ${ }^{a}$ ss_lisj@ujn.edu.cn, ${ }^{b}$ ss_tongyr@ujn.edu.cn, ${ }^{c} s s_{-} s u y @ u j n . e d u . c n$ \\ *通讯作者
}

\section{摘要}

创新能力培养是目前高校人才培养质量的一个重要目标, 本研究采用项目驱动法, 利用 “雨课堂” 智 慧教学平台, 对《传感器原理与应用》课程进行了一系列改革和尝试, 取得了较好的效果。本文主要 从课程现状分析出发, 阐述了课程改革的思路。重点介绍了课程改革的教学实践工作, 包括在教学资 源库建设、项目驱动教学法的构建、多样化考核评价体系建设等方面所作的努力和尝试。混合式教学 模式的应用使得项目驱动的效果非常明显，与课程内容结合紧密的项目设计对提升大学生的创新能力 具有积极作用。

关键词: 项目驱动法, 创新能力, 雨课堂, 混合式教学模式, 传感器

\section{1. 引言}

传感器是获取自然科学领域信息的主要途径和手段, 《传 感器原理与应用》课程是光电、测控、自动化、机电一体 化等专业的重要专业课程。由于传感器技术涉及物理、光 学、半导体、电子、信息、材料、化学等多学科知识, 信 息量大, 涉及范围广, 与生产实践结合紧密, 这与当前多 学科交叉融合的趋势相一致, 在专业课程体系中起到了重 要的承上启下作用。从本课程开始奠定的工程设计与应用 思想、创新实践能力和创新思维能力基础, 在现代高素质 专业人才培养中所起的重要作用是不言而喻的。

“项目驱动法” 的主体是学生, 通过完成具有明确目的性 的项目而掌握相关的专业技能, 在教师的指导下结合小组 项目进行分组讨论和专题研究, 通过实际调研来调动学生
的主观能动性, 充分挖掘学生的潜力, 发挥学生的创新思 维能力, 是实现“问题引导, 项目驱动, 学生为主”的教学 新模式, 对提高学生的综合素质具有实质性的意义[1]。 教育部在 2018 年出台《关于狠抓新时代全国高等学校本 科教育工作会议精神落实的通知》，要求淘汰“水课”、 打造“金课”。文件中提出的“金课”是指有深度、有难度、 有挑战度的课程。“金课”建设要求以求真为方法、以务实 为基本、以创造为目标、以自识为目的, 突破了原有课程 体系中知识在主客体间单向流动的直限, 致力于重构学生 “深度学习”的体验, 是我国高等教育领域一次深刻的课程 变革[2]。采用项目驱动教学法开展《传感器原理与应用》 课程的教学改革, 能够从本质上调动学生的学习积极性, 以学生为主体, 教师为主导, 加强学生的综合应用能力和 创新能力的培养。 
作和学习中能够和勇于面对挑战和遇到的困难, 积极寻求 解决办法, 从而提高思维和创新能力[4]。

\section{1. 理论分析与实践应用结合不够紧密}

传感器课程的教材往往以理论分析为主,多数教材是按照 各种传感器的结构、原理及应用为框架进行设计的, 与实 践联系最为紧密的应用部分往往简略带过。作为专业课程 教材, 内容更新较为滞后, 无法把最新的科技进展和应用 及时地展示给学生。教师在讲授过程中, 多数时候局限于 课本, 侧重于对各种类型的传感器进行工作原理和基本结 构的讲解分析, 对其实际应用的研究多停留在表面和理论 介绍上, 较难使学生对生产实践中的传感器有很具象的理 解和认识, 从一定程度上导致了学生学习兴趣不高, 缺乏 进一步探究的欲望。

\section{2. 教学手段单一, 互动性和参与度低}

传感器课程作为一门综合程度较高的专业课程, 一般开设 在大三下学期或者大四上学期。该阶段的学生已经学完了 各专业的基础课程和先修课程, 有能力将涉及到的多课程 知识融会贯通, 综合应用。但是在实际授课过程中, 教师 会发现实际情况并非如此, 学生学习兴趣并不高。究其原 因, 因为该阶段同时也是学生考研准备的重要时期, 绝大 多数学生都投身于考研大军中, 力求通过大学阶段的努力 使自己的学业和生涯规划能够通过读研这一高阶进程更 好地完成。由于报考重点院校的竞争压力巨大, 学生们不 愿意在非考研课的学习上投入过多精力, 尽管这些课程对 他们今后的学业发展可能会很有帮助。因此, 高年级课堂 上, 经常会出现教师的讲课即使非常精彩, 也难免变成“独 角戏”的処监尬, 学生对课程的参与度很低。教师在多次 “挫 败感” 的打击下, 可能也不愿意继续在教学中投入大量精 力, 久而久之形成了一种恶性循环。

\section{3. 考核方式缺乏过程性评价}

目前该课程考核主要采用总结性评价, 即以期末考试笔试 成绩为主, 占比 70\%-80\%, 平时的出勤和作业占 30\%-20\%, 缺乏过程性评价与管理。在个别学校和课程中, 由于学生 学习积极性不高, 对课程内容掌握情况较差, 为了避免不 及格率太高, 有些教师还会考前划重点, 降低考试难度等, 这进一步加剧了 “平时不学习、考前抱佛脚” 的现象, 极 易形成恶性循环。

\section{3. 课程改革的思路}

美国 20 世纪一流大学课程变革律使课程完成了三个重要 的逻辑转向, 即由知识向度向思维向度转变、由规定性话 语体系向开放性话语体系转变、由单一性向综合化转变 [3]。这些转向为我们进行课程建设提供了重要的理论参 考。

作为一门应用性极强的专业课程, 教师在授课过程中仅仅 将内容局限在课本所划定的框架中是不够的, 应该通过教 学模式的变革培养探究驱动型学习者, 使学生在未来的工

\section{1. 凸显 “学生中心” 的教学设计}

教学设计是上好一门课的重要环节, 是使课堂教学活动得 以顺利进行的基本保障。传统教学设计的关注点往往集中 在教师的 “教” 上, 主要针对教师的讲授活动进行设计, 力图把教学大纲的要求通过教师的 “讲” 传达给学生, 对 学生的需求和接受情况缺乏必要的关心。项目驱动法是以 学生为中心的, 这就要求教师在进行教学设计的时候, 必 须改变传统思路, 以全新的视角去思考学生的所思、所学 和所需, 进而根据学生特点, 运用系统的观点与方法, 分 析教学中的问题和需要, 确定教学目标, 建立解决问题的 步骤, 合理组合和安排各种教学要素, 充分体现教师的 “导”。

\section{2. 组建 “学习小队” 引导自主学习}

学习积极性是指学生在学习活动中所表现出来的一种认 真、紧张、主动和顽强的状态。学习积极性不仅为学习活 动提供动力, 影响学习的方向和过程, 而且进一步决定学 习的效率和效果。在教学活动中, 如何充分发挥教师的导 向作用, 调动学生学习的主动性、积极性, 把蕴藏在学生 身上的巨大潜力挖掘出来, 是确保教学质量的关键。传统 教学模式以教师讲授为主, 学生只能被动接受书本知识, 学习积极性不高。以项目驱动法为导向, 通过协同教学模 式中 “学习小队” 的建立鼓励学生积极思考, 加强队友之 间的互动与合作, 为其提供更多课堂参与机会, 使得学生 更容易感受到他们对项目设计完成做出了有价值的贡献, 实现自我满足与肯定, 从而提高学习兴趣与质量。

\section{3. 注重课堂反馈与教学反思}

在传统的教学过程中, 仅依靠多媒体课件来实现课堂互动 和获取及时反馈并不是一件容易的事, 教师只能通过观察 学生的表情和状态粗略判断学生对所授知识掌握与否, 如 果学生听课状态不佳, 则无从客观准确地了解授课效果。 当然, 作为一种补充手段, 教师可以通过课后的调查问卷、 谈话、测试等手段来获得进一步的信息反馈, 但是不可避 免具有滞后性。随着各种电子交互平台和手机 app 的出现, 混合式教学慢慢成为主流。教师可以充分利用各种各样的 网络资源, 借助雨课堂、超星等智慧教学平台, 在课堂上 就可以通过多样化的测验和调查问卷等形式即时获得有 效的信息反馈, 这是传统教学手段所不能比拟的。良好有 效的教学反思是提高教师教学效果的一种有效手段,可以 借助雨课堂给予的课程报告, 教师能够对每节课的效果进 行有效的反思, 查漏补缺, 提高进步。

\section{4. 注重过程化考核, 强调考核内容多样化}

以雨课堂为辅助手段, 采用项目驱动法进行课堂教学时, 应将考核的重点放在学生对项目的参与程度和贡献大小 
顺序, 使得理论知识能够通过项目的实施使学生亲自经历 一个完整的工作过程, 包括调研、分析、出方案、改方案、 实施、修订、完成等一系列过程, 逐渐完成书本知识向实 际应用的转化, 并在此过程中完成某些知识的自主学习。 教学方案的设计过程中, 通过对教与学的各个方面进行系 统分析, 结合雨课堂每次课后提供的课堂报告不断修正方 案, 从而使整个教学设计和教学方案得以连续不断地改进 和提高。由于增加了利用雨课堂工具设计的每堂课 4 5 个随堂小测验功能, 教师能够在答题结束后立刻看到以柱 状图显示的答题情况, 该图会实时显示在大屏幕上, 有助 于学生实时了解课堂里其他同学对这一知识点的掌握情 况。对于大多数学生而言, 实时了解同伴的学习成效对其 所造成的刺激, 要远大于教师把这个题的正确答案讲解出 来, 特别是对于基础一般的学生来说更是这样[6]。同时, 教师也可以通过自己的手机查看不同选项的学生选择情 况, 既有利于及时解惑错误选项, 也便于在课后对知识掌 握程度较差的学生进行有针对性的指导。

\subsection{2. 以项目为驱动, 采用线上-线下混合教学 模式}

实践证明, 知识在迫切需要的时候是学习掌握得最快最好 的时候。在认真分析该课程特点的基础上, 结合我校光电 专业学生参与的全国大学生电子设计竞赛、山东省光电科 技创新大赛等重要赛事, 借鉴相关题目, 寻求竞赛项目与 课程内容的相关点与结合点, 设计适用于该课程教学所需 要的 “项目”, 比如无线充电的循迹小车、蔬菜大棚的温 湿度检测及自动控制、厨房安全报警器等等。以此为契机 和导向, 引导学生开展对理论知识的深入研究和探讨, 达 到了以赛促学的作用, 提高了他们学以致用, 探求新知, 勇于创新的能力。

线上-线下的混合式教学是目前高等教育的热门话题, 当 前高等教育的主要参与者—— “95 后” “00 后” 大学生 一一的信息或知识获取方式已经发生了深刻变化, 表现在: 手机已成为学生生活中不可或缺的一部分; 学生的认知规 律以建构主义为主要特征, 他们已经习惯于从多个不同渠 道获取信息, 对碎片化的信息非但不反感, 反而会倍感亲 近, 这一点从抖音 APP 和哔哩哔哩网站在学生群体中大 行其道的趋势就可以看出; 学生对学习和课程的预期呈现 出多样化的趋势等[7]。

通过项目驱动教学法, 师生共同完成一个完整的项目工作, 教师根据课程特点, 将一个相对独立的项目交由学生自己 处理, 从信息的收集、方案的设计, 到项目的实施及最终 评价, 都由学生自己负责。学生通过该项目的进行, 了解 并把握整个过程及每一环节中的基本要求, 最终完成项目 所要求的产品。比如根据全国大学生电子设计竞赛题目中 的 “模拟电磁曲射炮” 设计的项目, 通过课前提供曲射炮 的相关视频和文字资料, 让学生对电磁炮有一个初步了解, 课堂上引导学生对项目要求进行分析, 对各环节可能会涉 及到的知识点进行研判, 之后结合教学内容, 分别有针对 性的进行讲解, 最后由各小组自行设计实施方案并进行制 作测试等。在方案的设计阶段, 可以针对 “学习小队” 的 内部讨论, 结合雨课堂的 “投稿” 功能, 将比较有代表性 的讨论方案投影到屏幕上供全班讨论, 同时还可以匿名或 实名同步到所有学生的手机上, 便于大家查看。该教学模 
式的应用极大地改变了原来较为沉闷的课堂氛围, 有利于 学生进一步打开思路。

\section{3. 制定行之有效的多样化考核评价体系}

在该研究中, 通过线上线下的混合式教学研究, 加以 “项 目”任务的分配与实施监管, 可以最大限度地避免传统考 核方式比较单一的问题。在项目的实施过程中, 每个学生 付出的努力和做出的贡献是不一样的, 教师需要在真个教 学过程中都密切关注每个学生的动态, 包括课下的学习情 况, 课上的参与情况, 以及在整个项目小组中所承担的角 色及起到的作用。所有这些都作为期末成绩的重要组成部 分, 考核的重点覆盖了整个教学过程。在项目驱动下, 为 了获得更好的学分绩点, 学生必须付出更多的精力和努力, 才能获得理想的分数, 这就避免了期末临阵磨枪的情况。 通过实践, 目前的考核方式包含三大部分, 线下学习 $10 \%$, 课堂讨论 $20 \%$, 项目完成情况 $10 \%$, 作业 $10 \%$, 出勤 $10 \%$, 期末考试 $40 \%$ 。考核的每一部分成绩都会及时反馈给学 生, 便于学生了解和掌握自己的得分情况, 在后续的学习 中查漏补缺。

\section{5. 结论}

创新型人才是国家进行技术创新、知识创新、服务创新的 关键主体, 而高校是创新人才培养的主要渠道, 新工科建 设的精髓在于提升大学生的创新能力和创造力 [8]。通过 改革, 极大地提升了学生对传感器课程的学习兴趣, 亲身 体验到了团结协作历经波折完成一个项目后成功的喜悦, 课堂参与度和活跃度明显提高。与课程内容结合紧密的项 目的实施使学生体会到了学以致用的快乐, 并在这个过程 中发现不足, 主动学习。在完成项目基本要求的基础上, 通过自行拓展新的功能将创新能力的培养贯穿在了整个 教学过程当中, 是一种非常有意义的尝试。

\section{致谢}

本文为教育部产学合作协同育人项目支持的阶段性成果 之一(No. 201901292016)。

\section{参考文献}

[1] 王凤香. “项目驱动法” 下以学生为中心的应用型本科 统计学教学改革探析 [J]. 教育教学论坛, 2019, (38): 121-122.

[2] 孙芳,王凯.20世纪美国一流大学本科课程变革的“遗 产”一一兼论对我国 “金课”建设的启示 [J]. 黑龙江高教研 究,2019,10(306):6-10.

[3] 谷慧娟. 我国大学课程话语的实践性转向 $[\mathrm{J}]$. 江苏高 教, 2018(3):53-54.

[4] 郭德红,李论.美国大学跨学科课程的开发及启示 [J].北 京教育:高教, 2015(9):80.

[5] 孙康宁,于化东,梁延德. 基于新工科的知识、能力、实 践、创新一体化培养教学模式探讨 [J]. 中国大学教
学,2019,(3):93-96.

[6] 姚洁,王伟力.微信雨课堂混合学习模式应用于高校教 学的实证研究 [J].高教探索,2017(9):50-54.

[7] 于歆杰. 论混合式教学的六大关系 [J]. 中国大学教学, 2019(5):14-18.

[8] 薛二勇. 协同创新与高校创新人才培养政策分析 [J]. 中 国高教研究, 2008( 12) : 26-31. 